\title{
Assisted colonisation trials for the western swamp turtle show that juveniles can grow in cooler and wetter climates
}

\author{
Alexandra Bouma ${ }^{1}$, Gerald Kuchling ${ }^{1,2}$, Sherry Yi Zhai ${ }^{3}$, Nicola Mitchell ${ }^{1, *}$ \\ ${ }^{1}$ School of Biological Science, The University of Western Australia, 35 Stirling Highway, Crawley, WA 6009, Australia \\ ${ }^{2}$ Department of Biodiversity, Conservation and Attractions, Parks and Wildlife Service, Wanneroo, WA 6065, Australia \\ ${ }^{3}$ School of Earth and Environment, The University of Western Australia, 35 Stirling Highway, Crawley, WA 6009, Australia
}

\begin{abstract}
Species with restricted ranges and long generation times are vulnerable to climate change due to limited opportunity to disperse or adapt. Australia's rarest reptile, the western swamp turtle Pseudemydura umbrina, persists naturally in only one seasonal swamp that holds water in the Austral winter and spring. A marked reduction in winter rainfall in recent decades has shortened the swamp hydroperiod, restricting when turtles are able to feed, grow and reproduce. To mitigate possible future loss of reproductive capacity in the native habitat, assisted colonisation was trialled in 2016 using 35 captive-bred juveniles. Here, we report the outcomes of this 6 mo trial, which compared the growth of turtles released approximately $300 \mathrm{~km}$ south of the species' indigenous range with growth of turtles released at an existing northern translocation site. We showed that growth rates comparable to those at warmer northern translocation sites can be achieved in the south, even in an atypically cool spring as occurred in 2016. Microclimates available to $P$. umbrina at 2 southern sites were suitable for foraging and growth in late spring and early summer, but juvenile growth at one southern site was significantly better than at the other, likely due to higher prey biomass when water temperatures were suitable for foraging. These early results suggest that introduction of $P$. umbrina to seasonal wetlands near the south coast of Western Australia could be considered in the immediate future, but further trials are recommended to assess growth and survivorship over longer periods.
\end{abstract}

KEY WORDS: Assisted colonisation · Translocation · Climate change · Turtle $\cdot$ Wetland $\cdot$ Growth Hydroperiod $\cdot$ Pseudemydura umbrina

\section{INTRODUCTION}

Climate change is one of the most significant threats to biodiversity this century (Pereira et al. 2010, Dickinson et al. 2014), and is rapidly shifting the conditions that dictate the structure and function of ecosystems (Walther et al. 2002, Parmesan \& Yohe 2003, Parmesan 2006, Williams et al. 2008). One of the most recognised impacts is a systematic shift of the poleward range limit of a variety of taxa (Hughes 2000, Walther et al. 2002), occurring along the same trajectory as climate change, at an average of 17 and

\footnotetext{
${ }^{*}$ Corresponding author: nicola.mitchell@uwa.edu.au
}

$72 \mathrm{~km} \mathrm{decade}$ der $^{-1}$ forrestrial and marine taxa respectively (Parmesan \& Yohe 2003, Pecl et al. 2017). The accelerated rate at which global climatic shifts are occurring places pressure on rangerestricted species, as geographic isolation reduces their ability to track climatic changes and relocate to more suitable areas (Parmesan 2006, Williams et al. 2008, Gibson et al. 2010). Furthermore, species with long generation times have limited potential for genetic or evolutionary adaptation in such rapidly changing environments (Meynecke 2004, Urban et al. 2014, Urban 2015). Without the capacity to move

() The authors 2020. Open Access under Creative Commons by Attribution Licence. Use, distribution and reproduction are unrestricted. Authors and original publication must be credited. 
or adapt, many species will go extinct as a direct result of climate change (Thomas et al. 2004).

Worldwide, reptile species are experiencing significant declines, with an estimated $25 \%$ of species at risk of extinction (Gibbons et al. 2000, Böhm et al. 2016) predominantly due to habitat loss and degradation and climate change (Gibbons et al. 2000, Sinervo et al. 2010). Turtles (order Testudines) are particularly imperilled relative to other larger vertebrate orders, with $52 \%$ of species threatened (Rhodin et al. 2018). The threat of climate change is amplified for turtles and other ectotherms due to their fundamental reliance on a particular range of environmental temperatures for maintaining physiological performance (Walther et al. 2002, Böhm et al. 2016). Although increases in global temperatures may elicit faster growth rates and earlier sexual maturity (e.g. Mitchell et al. 2012, Zuo et al. 2012), heat stress induced by sustained periods at high temperatures interferes with the regulation of metabolic functions (i.e. growth and reproduction), resulting in reduced fitness (Sinervo et al. 2010, Kingsolver et al. 2013). Reptile behaviours are also influenced by changes to microclimates. While time budgets for basking, resting and foraging can be adjusted under new microclimates to improve physiological performance (Böhm et al. 2016), some species may be unable to meet their energetic requirements in warmer conditions, resulting in reduced growth and survival (Sinervo et al. 2010, Buckley et al. 2015). The magnitude of these impacts is likely to be substantial for freshwater reptiles, as aquatic environments have narrower temperature ranges than terrestrial environments, limiting the availability of thermal refugia under warmer conditions (Pratchett et al. 2011). Further, freshwater habitats in drying climates may shift from being permanent to seasonal, rendering some habitats completely unsuitable for the species that currently utilise them (Walther et al. 2002, Pratchett et al. 2011).

The Critically Endangered (Burbidge et al. 2010) western swamp turtle (or tortoise; Pseudemydura umbrina) is endemic to Western Australia, with only 40 adults surviving in small conservation reserves $30 \mathrm{~km}$ north of Perth (see Fig. 1). Little is known of the species' past distribution, but ecological evidence and anecdotal information suggests that the indigenous range encompassed winter-wet swamps on the Swan Coastal Plain, between Mogumber in the north and Pinjarra in the south (Burbidge 1967, Burbidge et al. 2010). Habitat loss due to urban and agricultural expansion has been the primary driver of past population declines, but groundwater abstraction and climate change are major new threats that have contributed to the demise of the original Twin Swamps population (Burbidge et al. 2010). Winter rainfall in the southwest of Western Australia has reduced by approximately $26 \%$ since the 1970 s (CSIRO \& Bureau of Meteorology 2018), heavy rainfall events have diminished (Philip \& Yu 2020), groundwater has declined (McFarlane et al. 2020) and summers have become hotter (CSIRO \& Bureau of Meteorology 2018). All these processes shorten swamp hydroperiods, which define the activity season of $P$. umbrina (Burbidge 1981, King et al. 1998). Historically, swamps held water from May-June for 5-7 mo, and hatchlings consistently grew to large sizes before their first aestivation (Burbidge 1967). However, in recent years of low rainfall, hydroperiods in P. umbrina habitats have shortened to 3-4 mo (Arnall 2018). Consecutive years of short hydroperiods limit foraging opportunities, constrain the capacity of females to accrue energy for reproduction (Arnall et al. 2019) and prevent hatchlings growing to a critical size that prevents desiccation during their first aestivation period (Mitchell et al. 2012, Arnall et al. 2015). Shortening hydroperiods have also been observed at 2 northern translocation sites for P. umbrina (Mogumber and Moore River Nature Reserves) established in the past 2 decades (P. Muirdon unpubl. data), and projections from ecohydrological models indicate that hydroperiods will continue to decline (Mitchell et al. 2013). Such translocations to drier and warmer climates may ultimately fail, highlighting the need for innovative conservation practices to avoid the species' extinction.

Assisted colonisation (also assisted migration, managed relocation), is the intentional introduction of a species of conservation concern to an area outside of its indigenous range (IUCN/SSC 2013), and has gained traction as a strategy for mitigating the impacts of climate change on threatened species (McLachlan et al. 2007, Seddon et al. 2015). Opponents of this strategy appropriately highlight the risks of introducing a species to a new habitat and the uncertain impacts upon recipient ecosystems (Ricciardi \& Simberloff 2009). However, assisted colonisation has the potential to protect threatened species and build climate-resilient ecosystems (Seddon 2010, Lunt et al. 2013), provided it can be done within an adaptive management framework.

The current habitats of $P$. umbrina are likely to be irreversibly altered under future climate change unless major drought-proofing actions can be implemented. Assisted colonisation has become an option of strong interest to conservation managers, as $P$. umbrina is unlikely to adapt rapidly to a new climatic regime (generation lengths are at least 15-20 $\mathrm{yr}$; 
Mitchell et al. 2012), and because any suitable habitats nearby have been altered or destroyed. Hence, following a decade of research on methods to identify optimal translocation sites outside the indigenous range (Mitchell et al. 2012, 2013, 2016, Dade et al. 2014, Arnall 2018), a decision to trial assisted colonisation was made by the species recovery team.

Wetlands near the south coast of Western Australia are cooler than $P$. umbrina's current habitats, but have longer hydroperiods and are likely to provide ideal microclimates within 30-50 yr due to climate change (Mitchell et al. 2013). The objective of the trial was to assess the current suitability of southern coastal habitats for supporting populations of P. umbrina, with a longer term goal of establishing new populations should trials be successful. We expected that $P$. umbrina released at southern sites would grow more slowly than turtles released at a northern site, but predicted that slower growth rates could be offset by the longer hydroperiods over which individuals forage and gain mass. Here, we quantified growth rates of $P$. umbrina at 3 sites, assessed the thermal variation in swamp microclimates, and analysed the factors that influence juvenile growth. Taken together, our data provide strong indicators as to whether $P$. umbrina could persist in southern wetlands whose current microclimates are near the lower limit of their currently understood thermodynamic niche (Mitchell et al. 2013).

\section{MATERIALS AND METHODS}

\subsection{Translocation sites and study animals}

Two wetlands near the south coast of Western Australia (hereafter East Augusta and Meerup) were selected as trial sites for assisted colonisation, and an existing translocation site at Moore River Nature Reserve was selected to provide a comparison (Fig. 1). The southern wetlands were identified by spatial analysis (Dade et al. 2014) and assessed for thermal and hydrological suitability via mechanistic speciesdistribution modelling (Mitchell et al. 2013, 2016); site visits by G.K. confirmed their structural similarity to existing habitats. The trial was endorsed by the Western Swamp Tortoise Recovery Team, and approved by the Western Australian Department of Biodiversity Conservation and Attractions (Animal Ethics Approval no. DPW-AEC 2016-19).

A total of 35 juvenile turtles with an average mass of $130 \mathrm{~g}$ were sourced from the captive breeding colony at Perth Zoo. Individuals were mostly 2-5 yr

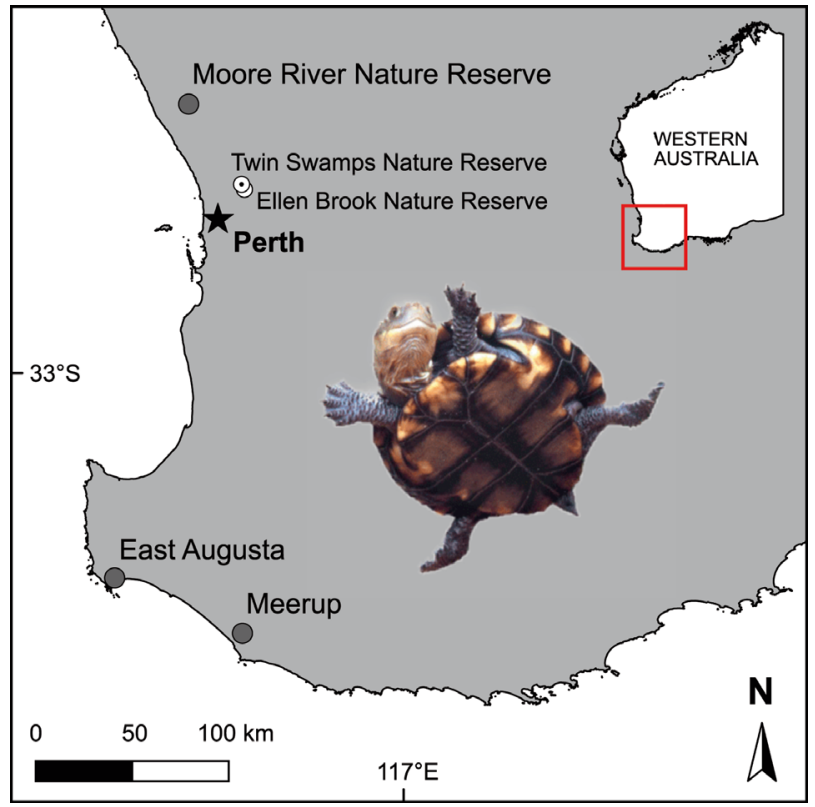

Fig. 1. South western Australia, showing the location of natural populations of Pseudemydura umbrina at Twin Swamps (the population at Twin Swamps Nature Reserve now consists only of animals reintroduced from captivity) and Ellen Brook Nature Reserves (EBNR), the established translocation site at Moore River Nature Reserve $(70 \mathrm{~km}$ north of EBNR) and the 2 sites for the assisted colonisation trials at East Augusta (290 km south of EBNR) and Meerup (330 km south of EBNR)

old, but one slower growing turtle was $10 \mathrm{yr}$ old. Pseudemydura umbrina show rapid growth in their first year and slower rates thereafter (Mitchell et al. 2012, Arnall et al. 2019); hence, we ensured a similar distribution of age and mass in each of 3 release groups to minimise any impact of these covariates on growth after translocation.

Perth Zoo incubates $P$. umbrina under different incubation regimes, so the turtles used in the trial had different incubation histories; namely, constant $24^{\circ} \mathrm{C}$, constant $29^{\circ} \mathrm{C}, 24 \pm 2{ }^{\circ} \mathrm{C}$ and $29 \pm 2{ }^{\circ} \mathrm{C}$ (daily fluctuations). Further, 4 turtles originated from an undetected nest in a breeding pen. We analysed posthatching growth rates of juveniles reared in captivity (which included the 35 turtles selected for the trial but excluded any growth that occurred after release; see Text S1 in the Supplement at www.int-res.com/ articles/suppl/n043p075_supp.pdf) and found that incubation history affected growth in the first year $(p<0.001)$ and over a 3 yr period $(p=0.005)$. In both instances, incubation at cooler temperatures resulted in more rapid growth than incubation at higher temperatures (Fig. S1). Hence, incubation regimes were evenly represented among the 3 release groups to 
minimise any impact of incubation history on growth after translocation.

\subsection{Release and monitoring}

Prior to release, all turtles were fitted with a $6 \mathrm{~g}$ radio transmitter (Model RI-2B; Holohil Systems) and an iButton temperature logger (Thermochron DS1921G; Maxim Integrated Products). Grayson \& Dorcas (2004) demonstrated a strong correlation in external and cloacal temperatures of the turtle Chrysemys picta, making external measures of temperature a good proxy for body temperature. Temperature loggers and transmitters were each attached to the rear of the carapace using marine-grade epoxy resin and covered with black PlastiDip to waterproof and minimise visibility from aerial predators (see King et al. 1998). The mass of the transmitter, iButton, epoxy and PlastiDip was approximately $10 \mathrm{~g}$, which was $5.4 \%$ of the mass of the largest individual in the trial (185 $\mathrm{g}$ at release) and $10.1 \%$ of the smallest individual (99.2 $\mathrm{g}$ at release). We programmed iButtons to log every $30 \mathrm{~min}$, which increases detection of basking events that are often shorter than 60 min (King et al. 1998).

Turtles were released at the 3 sites in August 2016: 11 individuals were released at Moore River (10 August), and 12 released each at Meerup and East Augusta (11 August). Each site was visited 1 wk after release to relocate turtles using a VHF receiver (Sika; Biotrack) and a directional and stick antenna (Yagi; Titley Electronics); thereafter, turtles were relocated fortnightly for the duration of the hydroperiod, and approximately monthly once turtles moved overland or began aestivation. As a condition of translocation approvals, all individuals that could be recaptured from the southern sites were returned to Perth Zoo at the termination of the trial. Although the trial was approved for $12 \mathrm{mo}$, the recovery team elected to end the trial after approximately 6 mo due to 3 factors: (1) many turtles were losing transmitters as a result of normal scute shedding after growth, (2) reattachment of transmitters during aestivation was unadvisable due to possible disturbance of aestivation behaviours and (3) some turtles at East Augusta moved onto private property to find aestivation sites.

\subsection{Turtle microclimates and growth}

To evaluate the microclimates available to turtles at each site, temperature loggers (model DS1921G;
Thermochron iButton) were haphazardly deployed in unshaded (and hence more open) areas of the swamp at each translocation site. The loggers recorded temperatures in shallow water $(\sim 2 \mathrm{~cm}$ below surface), deep water (bottom of swamp) and $5 \mathrm{~cm}$ above the water in a typical location where juveniles might bask. Logging stations (Fig. S2) were established in triplicate at each site, and if necessary were relocated by up to $10 \mathrm{~m}$ near the end of the hydroperiod to deeper water, which allowed us to continue to compare 3 microclimates. At each site, ambient temperature was measured $1.5 \mathrm{~m}$ above ground level in a shaded location. Temperature loggers were programmed to record every 30 min for basking, shallow and deep water microclimates, and hourly for ambient temperatures, at the same times as the temperatures recorded on a turtle's carapace. Hydroperiod lengths could not be measured, as trials commenced when standing water was already present. However, the dates when standing water had evaporated at each site were noted, and were used to infer differences in hydroperiod length.

Growth of turtles throughout the trial was quantified through measurements of body mass (Pesola spring balance, $\pm 0.3 \%$ ), carapace length, carapace width, carapace height and plastron length (digital callipers, $\pm 0.01 \mathrm{~mm}$ ). Where possible (i.e. if a turtle could be relocated), growth data were collected fortnightly for the duration of the hydroperiod at each release site (until 17 November 2016 at Moore River and until 20 December 2016 at Meerup and East Augusta). All data were collected during daylight hours (07:00-18:30 h), and effort was made to measure turtles at similar times of day across all 3 sites. Turtles were not measured or otherwise disturbed during aestivation in case they left aestivation burrows, increasing predation risk.

\subsection{Statistical analysis}

All statistical analyses were conducted in R v.3.3.1 (R Core Team 2017), and data were checked for normality and outliers to ensure that they met the assumptions of parametric testing. Any instances where these assumptions were not met are noted in the results.

Mass was used to assess growth rate, as it is a better indicator of growth over short time scales relative to morphometric measures. Appropriate adjustments were made to each mass measurement in accordance with the equipment an individual carried at the time (i.e. iButton, transmitter and epoxy adhesive). The 
specific growth rate (SGR) of each individual was then calculated using the following formula:

$$
\mathrm{SGR}=\frac{\left[\ln _{m(f)}-\ln _{m(i)}\right]}{\text { Time }} \times 100
$$

where $\ln$ is the natural $\log _{,} m(f)$ is the final mass, $m(i)$ is the initial mass and time is the number of days between initial and final measurements (Mitchell et al. 2012). Individuals had different growth periods according to when they left the swamp to search for aestivation sites, and the dates that transmitters were shed also influenced the timeframe over which growth could be compared. Consequently, the SGR over the longest time interval was calculated for all individuals. For 24 individuals, the time interval was from release to either the beginning of overland movement or the end of the hydroperiod, and for 4 individuals SGRs were calculated over slightly shorter time periods due to loss of transmitters. Turtles with fewer than 6 wk of growth data were excluded from the analysis of SGR described below.

A linear regression model was used to determine if the SGRs of translocated turtles differed across the release sites. The model included site as the predictor variable and 5 covariates to test if any differences in growth rate were related to individual fixed effects. Covariates were age (in years), incubation regime (5 categories as described in Text S1 and Fig. S1), mass at release (measured at Perth Zoo on 21 or 22 July 2016), the SGR of each individual in its first year of life at Perth Zoo and a temperature correction factor (a constant temperature equivalent [CTE]) that integrated data on each turtle's body temperature during the growth period after its release. The CTE was calculated from the hourly shallow water temperatures (a proxy for turtle body temperature) measured at each site, trimmed to align with the dates over which the corresponding SGR was calculated. Temperature records were then converted into rates (based on the thermal reaction norm of resting metabolic rate of adult P. umbrina; Arnall et al. 2015), and integrated as described in Georges et al. (2005) to calculate the CTE. There was no significant interaction or collinearity between covariates included in the model. We then conducted a backward elimination regression, removing the covariates with the largest $p$-values one at a time until all terms in the model were significant $(p<0.05)$. Model comparisons were based on second-order corrected AICc for small sample sizes.

A 1-way ANOVA with pairwise Tukey post hoc comparisons was then used to determine at which sites $P$. umbrina exhibited significantly different SGR. Unequal variances were assumed due to small sample sizes, and all data were checked for normality through visual inspection of $Q-Q$ plots, distribution of residuals and histograms. Histograms showed small deviance from normality due to some outliers in the Meerup data, but this was considered acceptable as data were unlikely to be normally distributed due to the small sample size.

To assess differences in available microclimates across the translocation sites, average daily maximum and minimum temperatures were calculated for the duration of the hydroperiod. Some iButtons attached to logging stations at Moore River did not record from 23 September to 10 November 2016, in which case we reconstructed microclimates from the linear relationship between ambient temperatures and each of the microclimate temperatures (basking, shallow water, deep water) for periods where all data types were available. In some instances, data on ambient temperatures were missing, so we sourced ambient temperature data from a weather station maintained by the Western Australian Department of Agriculture (Lancelin East) located $35 \mathrm{~km}$ northwest of the site. All reconstructed data were used for visualisation purposes only. When iButton-derived data were available across the 3 sites ( $41 \mathrm{~d}$ between 12 August and 22 September 2016), we compared microclimates using 1-way ANOVA of daily minimum and maximum temperatures. Additionally, microclimates were measured at the southern trial sites for a further $83 \mathrm{~d}$ (28 September to 20 December 2016, demarcated by the end of the hydroperiod), in which case differences between the minimum and maximum temperature values at each site were assessed using 2-way $t$-tests.

We attempted to deduce the microclimates that turtles utilised at the southern sites by determining which microclimate temperatures aligned best with averaged turtle carapace temperatures throughout daylight hours (06:00-19:00 h; sensu Pittman \& Dorcas 2009). We identified dates where most turtle data were available and then arbitrarily selected $1 \mathrm{~d}$ each month from August to November 2016 for plotting. No statistical analysis was attempted, in recognition that comparisons of carapace temperature based on single dates could have been confounded by differences in solar radiation at each site.

\subsection{Climate trend analysis}

Growth in reptiles is influenced by annual variation in weather, particularly during the activity season 
(Adolph \& Porter 1996), so we conducted an a posteriori climate trend analysis to determine if the weather during the 2016 trial was typical. We conducted separate analyses for annualised data, and for data from July-December, which corresponds with the activity period of $P$. umbrina. In both cases, data on mean maximum air temperature, mean minimum air temperature and rainfall were obtained from weather stations located within $50 \mathrm{~km}$ of each site that had long-term data sets (at least $10 \mathrm{yr}$ of temperature data or $30 \mathrm{yr}$ of rainfall data). In addition to raw values, anomalies from the 1961-1990 climate average were calculated and then normalised. In brief, the $30 \mathrm{yr}$ average of 1961-1990 is the current international standard for the recent climate (CSIRO \& Bureau of Meteorology 2018); hence, for any one year, the anomaly is the rainfall difference from the 1961-1990 mean rainfall, and the normalised anomaly is the difference between the yearly anomaly and the mean of all anomalies from 1961-1990. For both air temperature and rainfall, statistical trends were examined in $\mathrm{R}$ using the 'autoregressive integrated moving average' (ARIMA) model of the 'forecast' package (Hyndman \& Khandakar 2008). For rainfall, 'cumulative deviations from the mean' (CDFM) were calculated to represent long-term rainfall trends (Emelyanova et al. 2013).

\section{RESULTS}

Of the 35 Pseudemydura umbrina released in the assisted colonisation trial, we were able to assess growth until near the hydroperiod end for 24 individuals, and so could evaluate a key criteria for translocation success - whether an animal was able to gain mass. However, radio transmitters and iButtons frequently detached from turtles throughout the trial, sometimes due to normal shedding of scutes, but also due to poor attachment due to a faulty batch of epoxy adhesive. For example, within the first week of release, 9 P. umbrina at East Augusta were returned to Perth to have transmitters and iButtons re-attached by G. K. with an improved adhesive. Ultimately, 16 turtles were transported to Perth for this $2 \mathrm{~d}$ procedure before being returned to their release sites within 3-4 d. These complications meant that not all turtles in each release group were relocated during each site visit, resulting in inconsistent sample sizes for growth measurements. Similarly, as iButtons were periodically shed and re-attached throughout the trial, continuous records of carapace temperature were not available for all turtles.
Hydroperiod lengths differed between northern and southern translocation sites, with swamps in the release areas at Meerup and East Augusta holding water 6-8 wk longer than at Moore River. At Moore River, swamps had dried completely by 11 November 2016, while at East Augusta water remained until 20 December 2016 in a trench dug to provide a refuge, but this had evaporated by 4 January 2017. At Meerup, shallow pools were present on 20 December 2016, but by 3 January 2017 the only standing water was at least $500 \mathrm{~m}$ from the release swamp. In the southern sites, all turtles had left swamps and commenced overland movements and aestivation behaviours by 20 December 2016.

Analysis of long-term climate data (Text S2) showed that the winter-spring months at Moore River and Meerup were wetter in 2016 than average, while the winter-spring period at East Augusta was drier and cooler than average (Tables S1 \& S2, Figs. S3-S5). Radio tracking revealed that all turtles were moving overland or beginning to aestivate at Moore River by 10 November, while at Meerup and East Augusta these behaviours were first observed on 20 December. Turtles were able to find suitable aestivation sites in the assisted colonisation sites in the south by using depressions under the skirts of grass trees Xanthorrhoea sp. or shallow burrows at the base of fallen logs. One Meerup turtle died in February 2017. In this instance there were no visible signs of predation but the animal was in poor body condition. No other turtles were known to have died during the trial.

Despite many turtles shedding radio transmitters, most were relocated by chance near the end of the hydroperiod at the southern trial sites. Once the decision to end the trial was made in January 2017 (see Section 2.2), 10 individuals that had been released at East Augusta were returned to Perth Zoo on 18 January 2017, and 2 turtles released at Meerup were returned between 8 February and 8 March 2017. Turtles released at Moore River were not collected, as this is an established translocation site. In total, 2 and 9 turtles whose radio transmitters had been shed remained at East Augusta and Meerup respectively at the end of the trial; one of the Meerup individuals was relocated in January 2019 by N. M.

\subsection{Turtle growth rates}

The average mass of juvenile $P$. umbrina throughout the first month of the trial was similar at each translocation site, but thereafter the average mass of 
juveniles at Moore River increased until the hydroperiod ended in mid-November (Fig. 2a). In contrast, juveniles at the 2 southern sites lost an average of $10 \mathrm{~g}$ over the first $2 \mathrm{mo}$ of the trial. After this initial loss, growth rates at East Augusta were comparable to those at Moore River until the end of the hydroperiod in late December (Fig. 2a). The mass of juveniles at Meerup fluctuated throughout monitoring, with little change in average mass over the trial period (Fig. 2a). Comparison of linear regression models showed that translocation site was the only factor that affected the SGR of juvenile $P$. umbrina $\left(F_{2,25}=9.46, \mathrm{p}=0.0008\right)$, as none of the 5 covariates
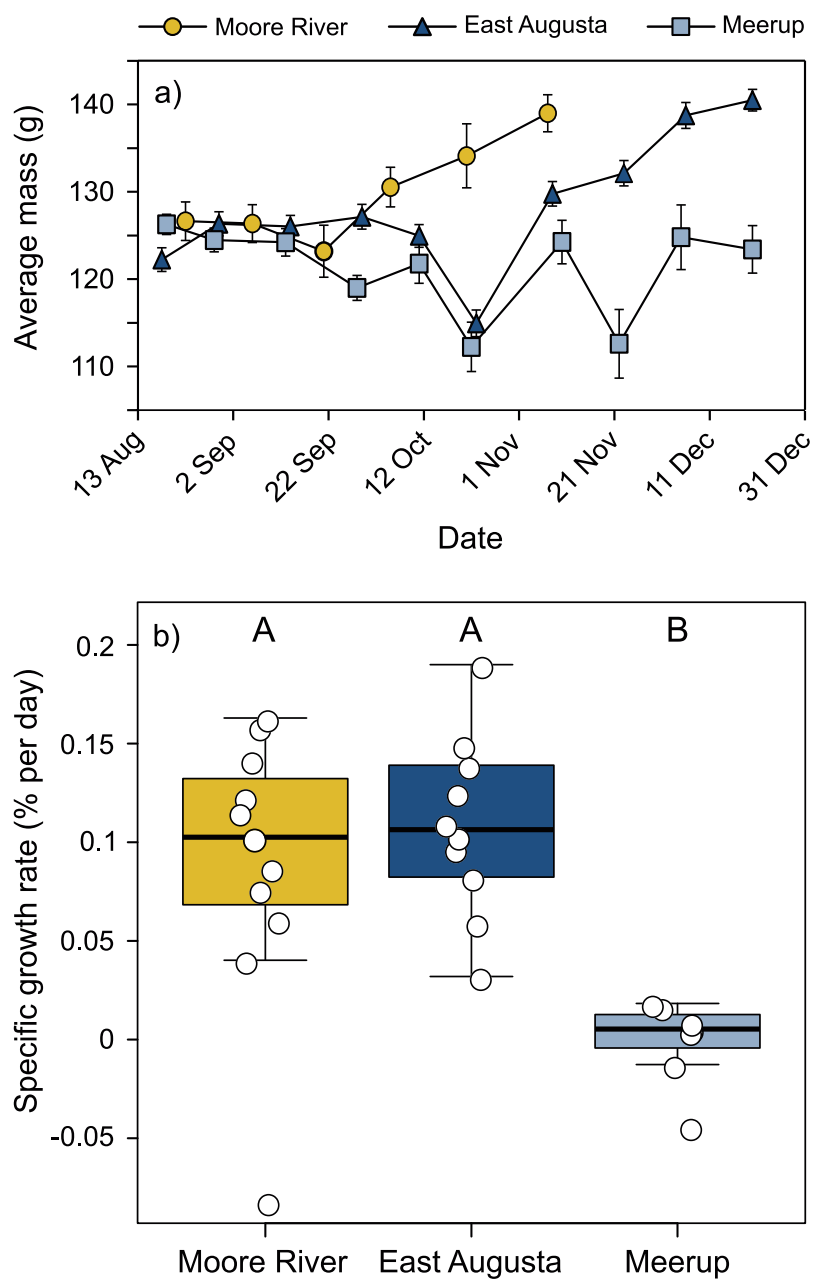

Fig. 2. (a) Average ( $\pm 1 \mathrm{SE}$ ) mass of Pseudemydura umbrina released at 3 translocation sites during the 2016 hydroperiods, and (b) box and whisker plots of specific growth rates at each release site. Lower and upper box boundaries: $25^{\text {th }}$ and $75^{\text {th }}$ percentiles respectively; thicker line inside the box: median; lower and upper error bars: $10^{\text {th }}$ and $90^{\text {th }}$ percentiles respectively; open circles: jittered raw data. Significant differences are indicated by different letters (ANOVA, Tukey's post hoc test, $\alpha=0.05$ ) included in the model were significant, and models that included covariates had lower support than the model that included only site (Table S3). Post hoc comparisons showed significant differences between SGRs at Meerup and East Augusta $(p=0.001)$, and at Meerup and Moore River $(p=0.004)$, but no significant difference between Moore River and East Augusta ( $p=0.6)$ (Fig. 2b).

\subsection{Microclimates of translocation sites}

There were clear differences in the aquatic microclimates available to $P$. umbrina at each translocation site - most notably, all microclimates at Moore River were warmer than those at Meerup and East Augusta in the first 6 wk of the trial (August and September; Table 1, Fig. 3). Across all sites, daily maximum basking and shallow water temperatures were within the activity range for $P$. umbrina $\left(14-30^{\circ} \mathrm{C}\right)$ for the duration of the trial, but deep water temperatures at all sites were below $14^{\circ} \mathrm{C}$ until approximately midOctober (Table 1, Fig. 3) and were significantly different between sites $\left(F_{2,123}=4.03, \mathrm{p}=0.02\right)$, with temperatures at Moore River being higher than those at East Augusta $(p=0.018)$. Daily maximum shallow water temperatures across the 3 translocation sites were also significantly different $\left(F_{2,123}=98.03, \mathrm{p}<\right.$ 0.001; August-September data), with each site being significantly different from the other $(p<0.001)$. Shallow water environments at Moore River had a smaller range of generally warmer temperatures than the southern sites (Fig. 3d-f). From late September until December, when only the southern sites could be compared, Meerup had significantly warmer shallow water temperatures than East Augusta $\left(t_{210}=\right.$ $7.05, \mathrm{p}<0.001$ ), with more pronounced differences from September to December (Table 1, Fig. 3e,f). There were no significant differences in the minimum $\left(t_{138}=0.7, \mathrm{p}=0.48\right)$ or maximum $\left(t_{138}=1.69, \mathrm{p}=\right.$ 0.09 ) deep water temperatures at the southern sites over the same time period.

Basking microclimate temperatures followed similar patterns to those of the aquatic microclimates: daily maximum basking temperatures across all sites between 12 August and 22 September 2016 were significantly different $\left(F_{2,123}=21.51, \mathrm{p}<0.001\right)$, with temperatures at Moore River being higher than those at Meerup ( $p<0.001)$ and East Augusta $(p<0.001)$. Daily minimum basking temperatures during this same period were also significantly different $\left(F_{2,123}=\right.$ 5.86, $\mathrm{p}=0.003)$, with temperatures at Moore River being higher than those at East Augusta $(p=0.002)$. 
Table 1. Indicative daily minimum, maximum and mean temperatures of basking, shallow water and deep water microclimates at the 3 translocation sites during the hydroperiod. Values are the averages from 3 logging stations established at each site. Data availability varied slightly in some months as follows: 'August' was 11-31 August at Moore River, and 12-31 August at Meerup and East Augusta; 'September' was 1-22 September at Moore River, 1-23 and 28-30 September at Meerup and 1-23 and 29-30 September at East Augusta; 'November' was 1-10 and 22-30 November at Meerup, with the full monthly data set available for East Augusta. (-) not available due to missing data

\begin{tabular}{|c|c|c|c|c|c|c|c|c|c|}
\hline & \multirow[b]{2}{*}{ Min. } & \multirow[b]{2}{*}{$\begin{array}{l}\text { Moore River } \\
\text { Mean }\end{array}$} & \multirow[b]{2}{*}{$\overline{\operatorname{Max}}$} & \multicolumn{2}{|c|}{$\begin{array}{r}\text { Temperature }\left({ }^{\circ} \mathrm{C}\right) \\
\text { East Auqusta }\end{array}$} & ) & \multirow[b]{2}{*}{ Min. } & \multirow[b]{2}{*}{$\begin{array}{l}\text { Meerup } \\
\text { Mean }\end{array}$} & \multirow[b]{2}{*}{ Max. } \\
\hline & & & & $\overline{\text { Min. }}$ & $\begin{array}{c}\text { East Augusta } \\
\text { Mean }\end{array}$ & $\overline{\operatorname{Max}}$ & & & \\
\hline \multicolumn{10}{|c|}{ Basking microclimates } \\
\hline August & 1.5 & 12.9 & 28.5 & 1.8 & 12.0 & 23.7 & 0.5 & 11.5 & 22.8 \\
\hline September & 1.7 & 13.2 & 28.3 & 3.5 & 12.4 & 24.2 & 2.2 & 12.0 & 24.5 \\
\hline October & - & - & - & 5.0 & 14.1 & 27.3 & 4.3 & 14.3 & 29.7 \\
\hline November & - & - & - & 6.8 & 17.1 & 34.8 & 4.8 & 17.1 & 33.7 \\
\hline December & - & - & - & 7.0 & 18.1 & 32.0 & 4.3 & 17.4 & 38.2 \\
\hline \multicolumn{10}{|c|}{ Shallow water microclimates } \\
\hline August & 9 & 14.3 & 23.5 & 8.7 & 12.1 & 14.7 & 8.5 & 13.2 & 19.2 \\
\hline September & 10.5 & 15 & 22.8 & 9.7 & 12.7 & 18.3 & 9.7 & 14.3 & 22.2 \\
\hline October & - & - & - & 10.3 & 15.2 & 21.0 & 10.5 & 17.6 & 27.2 \\
\hline November & - & - & - & 12.5 & 17.3 & 29.0 & 13.7 & 20.9 & 31.2 \\
\hline December & - & - & - & 11.5 & 17.5 & 43.0 & 11.1 & 20.6 & 37.3 \\
\hline \multicolumn{10}{|c|}{ Deep water microclimates } \\
\hline August & 9.3 & 12.5 & 21.2 & 9.2 & 12.2 & 13.8 & 9.2 & 12.1 & 14.0 \\
\hline September & 10.7 & 13.0 & 14.5 & 10.5 & 12.7 & 18.3 & 10.2 & 13.0 & 15.5 \\
\hline October & - & - & - & 10.7 & 15.0 & 19.2 & 10.7 & 16.0 & 20.2 \\
\hline November & - & - & - & 13.8 & 18.7 & 29.0 & 14.0 & 19.7 & 27.7 \\
\hline December & - & - & - & 11.8 & 19.6 & 33.2 & 12.3 & 20.1 & 33.7 \\
\hline
\end{tabular}
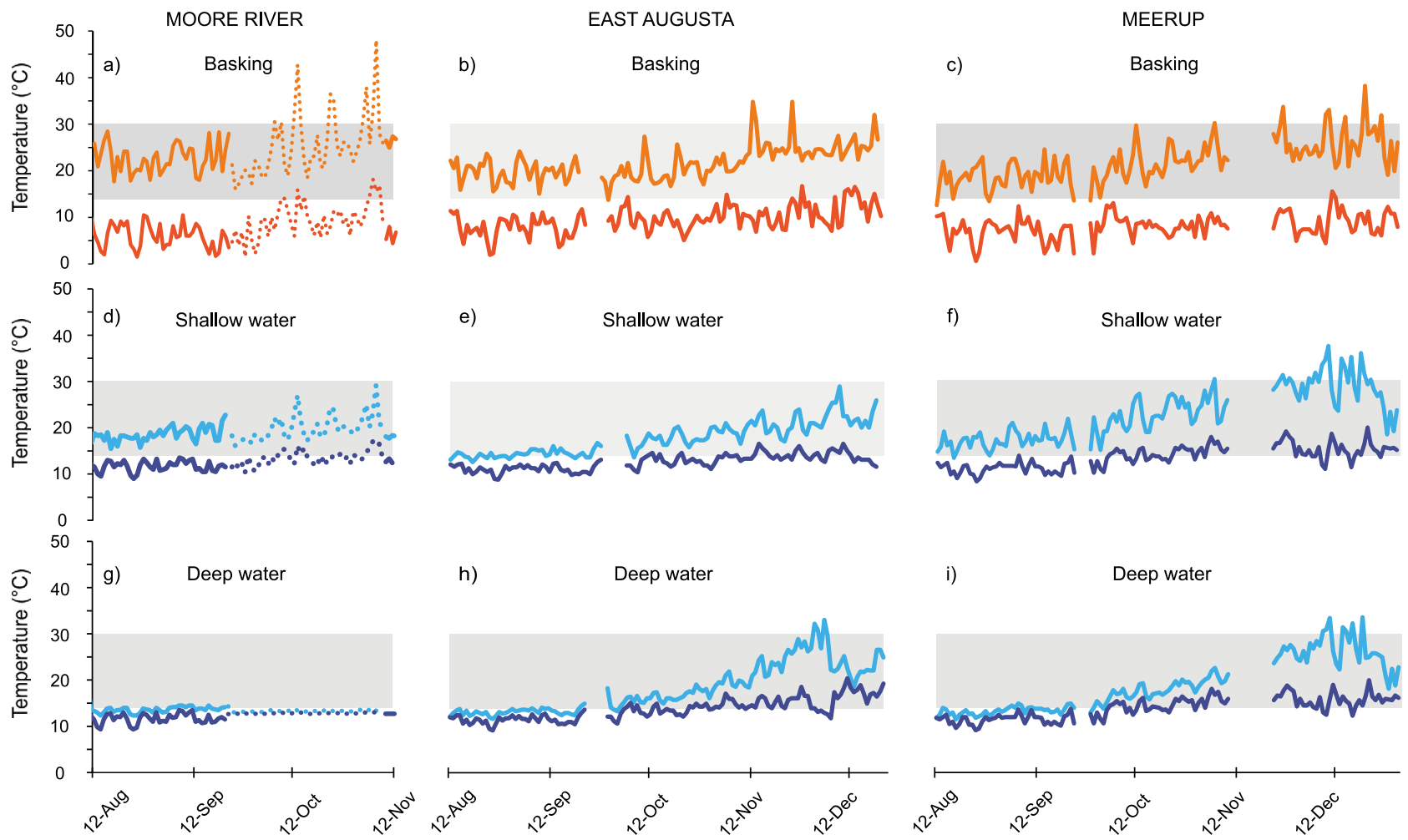

Fig. 3. Mean daily maximum temperatures (lighter lines) and mean daily minimum temperatures (darker lines) for (a-c) basking, $(d-f)$ shallow water and $(g-i)$ deep water microclimates at $(a, d, g)$ Moore River Nature Reserve, $(b, e, h)$ East Augusta and $(\mathrm{c}, \mathrm{f}, \mathrm{i})$ Meerup over the duration of the hydroperiods. Data at Moore River end on 10 November when the swamps dried. Dashed lines: reconstructed data; gaps: missing data; grey shading: temperature range $\left(14-30^{\circ} \mathrm{C}\right)$ at which Pseudemydura umbrina are active (Lucas et al. 1963, Burbidge 1967). Daily maximum and minimum values were averaged for 3 environmental stations located within the swamps at each site 
From September to December, daily maximum basking temperatures at Meerup were significantly higher $\left(t_{138}=2.43, \mathrm{p}=0.01\right)$ than those at East Augusta, but minimum basking temperatures were significantly lower at Meerup $\left(t_{138}=-4.56, \mathrm{p}<0.001\right)$, reflecting the narrower range of basking temperatures at East Augusta (Fig. 3b,c).

\subsection{Comparison of carapace temperatures across translocation sites}

During August and September at both southern sites, both aquatic microclimates were below or just within the critical thermal range considered suitable for $P$. umbrina activity (14$30^{\circ} \mathrm{C}$; Lucas et al. 1963, Arnall et al. 2015), and turtle carapace temperatures closely tracked these microclimates and only reached temperatures suited to activity near the end of the day (Fig. 4a-d). By late October, both shallow and deep water microclimates were between $14-30^{\circ} \mathrm{C}$ during daylight hours, and carapace temperatures recorded for Meerup turtles were similar to those of the shallow water microclimates, which were warmer than basking sites towards the end of the day (Fig. 4f). In contrast, on the same day at East Augusta, shallow water microclimates were colder than at Meerup, and juveniles operated at temperatures closer to those of the basking microclimate (Fig. 4e).

At the beginning of November (approximately 6 wk before southern swamps dried), all microhabitats at the southern sites were at suitable temperatures for activity in $P$. umbrina. Turtles at both sites exhibited a range of carapace temperatures throughout the day, most of which were substantially warmer than those captured by the microclimate temperature loggers (Fig. 4g,h). In general, turtles tracked water temperatures closely until approximately 10:00 h, after which time carapace temperatures both increased and fluctuated, suggesting
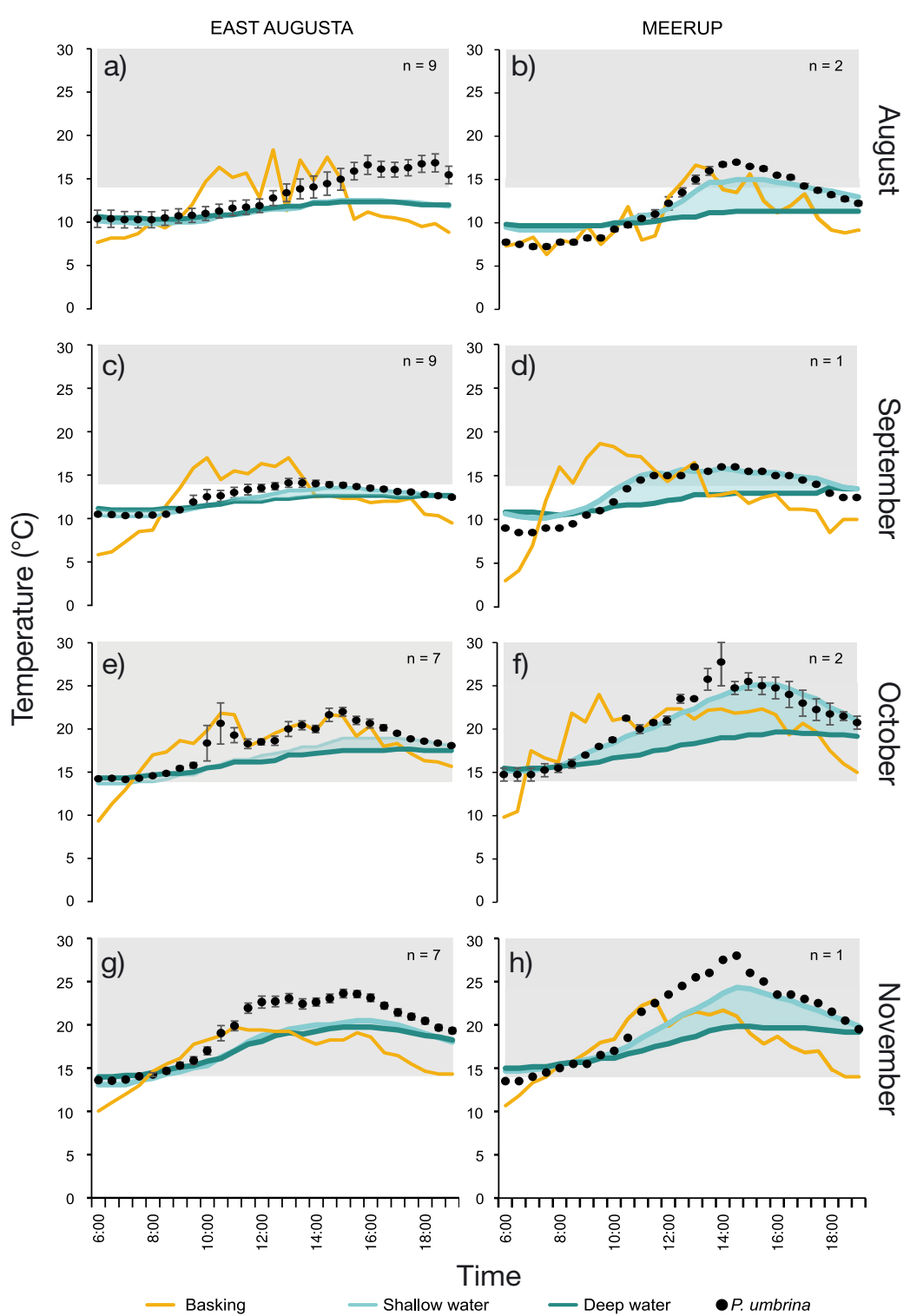

Fig. 4. Mean ( $\pm 1 \mathrm{SE}$ ) carapace temperatures of juvenile Pseudemydura umbrina ( $\mathrm{n}=$ no. of ind.) and mean temperatures of basking, shallow water, deep water and ambient microclimates between 06:00 and 19:00 h on 4 arbitrary dates at East Augusta and Meerup when the most turtle data were available: $(\mathrm{a}, \mathrm{b}) 18$ August, $(c, d) 18$ September, $(e, f) 28$ October and $(g, h) 8$ November 2016. These days were mostly sunny, with daily global solar exposure close to a typical value, given in square brackets, for the month - East Augusta: (a) 13.3 [11.3], (c) 11.2 [15.2], (e) 20.5 [19.6], (g) 22.4 [24.9]; Meerup: (b) 10.6 [10.6], (d) 13.0 [13.6], (f) 20.6 [18.7], (h) 20.3 [24.4]; all data from www.bom.gov.au, Cape Leeuwin and Northcliffe weather stations respectively. Areas between the deep and shallow water microclimates are filled to emphasise the contrasting range of water temperatures measured at the 2 southern sites. Grey shading as in Fig. 3 


\section{DISCUSSION}

This study reports a world first trial of assisted colonisation of a vertebrate species in response to the threat of climate change. Our fundamental objective was to determine if assisted colonisation to wetlands more than $300 \mathrm{~km}$ south of the indigenous range of Pseudemydura umbrina is a viable option for captive-bred juveniles. The capacity for turtles to gain mass during their winter-spring activity period was considered to be a good indicator of the ability of P. umbrina to persist in a novel habitat. At one of the assisted colonisation trial sites (East Augusta), juveniles achieved equivalent growth rates to those released at the established northern translocation site at Moore River. As growth at Moore River reflected the growth expected in the indigenous range, this result suggests that seasonal wetlands in the East Augusta area could be suitable for assisted colonisation of $P$. umbrina in the immediate future. However, as juveniles failed to gain mass at Meerup, despite experiencing similar hydroperiods as at East Augusta, there are clearly site-specific factors that contributed to these contrasting results.

One factor (based on earlier work of Mitchell et al. 2012) that we considered likely to influence juvenile growth rate was water and basking temperature. While microclimates were significantly different across translocation sites, each turtle's estimated temperature during their growth period (the CTE) was not a significant covariate explaining their SGR, nor did we detect significant differences in carapace temperatures of $P$. umbrina at the southern sites. Examination of the carapace temperatures relative to microclimate temperatures suggested that turtles at Meerup and East Augusta selected shallow water and basking microclimates in October and November. Aquatic basking is common in P. umbrina (King et al. 1998) and allows turtles to forage in cooler environments (Crawford et al. 1983). At East Augusta, the similarity in the carapace temperatures of $P$. umbrina and shallow water microclimates coincided with a period of higher growth from September to late November (e.g. Fig. 4c,f,g). Juveniles at this site were frequently found moving through warm, shallow water, which suggested they selected microclimates that met their thermal requirements while simultaneously providing opportunities for foraging.

A link between shallow water occupancy and physiological performance is supported by data from King et al. (1998), who showed that $P$. umbrina individuals that spent more time in warm water gained mass faster than those that spent more time in cold water. The temperature range for activity of $P$. umbrina is $14-30^{\circ} \mathrm{C}$, and performance is optimal between 22 and $28^{\circ} \mathrm{C}$ (King et al. 1998); hence, low water temperatures were the likely reason that $P$. umbrina translocated to southern sites did not gain mass until mid-September. The behavioural response of $P$. umbrina to colder temperatures $\left(<10-12^{\circ} \mathrm{C}\right)$ is to conserve energy by resting at the bottom of the swamp (Lucas et al. 1963). This behaviour was observed at both southern sites during daylight hours at Meerup and East Augusta, where carapace temperatures closely tracked deep water temperatures (Fig. 4). This passive behaviour likely resulted in preservation of energy, but also lack of growth as turtles were not able to forage.

Cold water temperatures that constrained activity were likely to be the key factor that prevented growth of translocated turtles at the beginning of the trial, but the lack of spring growth at Meerup, despite suitably warm microclimates, suggests that food resources were limiting at this site. Swamp turtles require abundant sources of aquatic invertebrates and tadpoles to feed on during their activity period (Burbidge et al. 2010), and a concurrent study of food resources at each translocation site (Schmölz 2018) showed that although biomass in the Meerup wetland was generally comparable to that at Moore River Nature Reserve, towards the end of the hydroperiod it did not increase, in contrast to the biomass at East Augusta. At East Augusta, the biomass of tadpoles increased threefold between early and late spring. So while the total biomass at Meerup was slightly higher in early spring than in East Augusta, it did not increase in late spring when the thermal environment was more suitable for foraging (Schmölz 2018). This suggests a phenological mismatch in prey abundance and suitable foraging microclimates at Meerup, which is problematic given that the relationship between temperature and foraging rates in reptiles is highly synergistic (Avery 1978, Grant 1990, Zug et al. 2001). In a previous study of captive-reared juvenile $P$. umbrina, food intake was the primary driver of rapid growth, while water temperature mediated higher rates of food intake (Mitchell et al. 2012). Hence, wetland biomass and the phenology of prey items should be important criteria when selecting sites for future assisted colonisations of $P$. umbrina; otherwise their reduced activity at lower temperatures cannot be offset by high food availability.

While $P$. umbrina were capable of gaining mass in the southern wetlands, even during months where water temperatures were below the accepted threshold for activity, growth of $P$. umbrina is clearly faster 
at higher temperatures (King et al. 1998, Mitchell et al. 2012). However, many ectotherms have higher fitness near the lower bounds of their thermal optimums (Bickford et al. 2010). This is likely to be true for $P$. umbrina, as their activity decreases more rapidly at higher temperatures than it does at lower ones (Lucas et al. 1963). Lucas et al. (1963) hypothesised that $P$. umbrina increase their body temperatures in cooler environments through reduced but continued activity, whereas sustained activity near upper thermal limits is likely to destabilise the metabolic processes necessary for survival. Furthermore, ectotherms from colder environments often reach larger body sizes at maturity (Angilletta et al. 2004), which may be beneficial for $P$. umbrina, as female body size is correlated with fecundity (Arnall 2018). These considerations mean that assisted colonisation to a suitable southern site could occur sooner rather than later, as any fitness cost of occupying cooler habitats may not necessarily be less than the impacts of consistently short hydroperiods in the species' indigenous range.

It will be necessary to consider landscape-scale site characteristics, not only swamp areas, when selecting areas for assisted colonisation-for example, the thermal suitability of terrestrial nests at candidate assisted colonisation sites has already been evaluated for P. umbrina (Mitchell et al. 2016). Importantly, the long-term suitability of any southern site will be contingent upon juvenile turtles being able to survive their annual period of terrestrial aestivation. The early end to our trial meant that aestivation behaviours such as arousal following low pressure systems or rainfall could not be compared across sites. Encouragingly, captive-reared juveniles found suitable aestivation sites at both southern sites, but as the East Augusta swamp was largely bounded by private property, it led to several individuals moving onto private land to aestivate. Appropriate land tenure (ideally conservation estate) is viewed by species experts as a key criteria in translocation site selection for $P$. umbrina (Dade et al. 2014), so the trial swamp at East Augusta is unlikely to be the best option for establishing a permanent assisted colonisation site. Fortunately, the nearby Scott River National Park may offer a suitable alternative to the East Augusta trial site, as it has similar vegetation and swamp characteristics, provides a much larger area and has little connectivity to farmland or private properties.

Although this study revealed clear differences in the apparent suitability of the trial assisted colonisation sites, several limitations need to be acknowledged. The first is small sample sizes, which were further diminished when radio transmitters and temperature loggers periodically detached from turtles throughout the trial. This reduced the power of statistical analyses, and limited the confidence in interpreting the behavioural responses of $P$. umbrina to the thermal microclimates available at each site. Secondly, data on carapace temperatures at Meerup came from only 1 or 2 individuals. Thirdly, the lack of microclimate data from Moore River meant we were unable to establish whether $P$. umbrina consistently utilised warmer microclimates in northern versus southern sites, and whether this could explain the marked increase in growth from September onwards. Finally, the south-west of Western Australia experienced below average temperatures throughout winter and spring in 2016 (see Figs S3 \& S4), which meant that the trial was conducted in an atypically cool period. As such, the results presented here are preliminary, but provide a solid basis to support further field trials in southern wetlands.

\subsection{Recommendations for future trials}

This study has provided important empirical data to guide the selection of a site for assisted colonisation of $P$. umbrina. Earlier modelling and spatial mapping studies that were focused on assisted colonisation of $P$. umbrina produced variable assessments on the suitability of each of the southern sites. For example, Dade et al. (2014) ranked the Meerup site (named Doggerup Creek) as 8 out of 12 possible sites, with food availability, site size and vegetation composition noted to be likely limiting factors. Additionally, Mitchell et al. (2016) found that under future climate change, the Meerup site had the lowest suitability for supporting embryonic development due to cool soil temperatures. This has important implications when considering permanent introduction rather than a trial, as the suitability of the swamp area for supporting juvenile growth is of little relevance if $P$. umbrina are unable to successfully hatch. East Augusta was previously identified as a site where food availability was ideal, but site size and land tenure were presented as key factors that reduced its suitability (Dade 2013). Notably, these predictions were borne out by the results of this trial. When combined with the findings presented here, it is clear that the assisted colonisation strategy for $P$. umbrina will need multi-faceted evaluation to ensure the best possible site is selected.

This study does not provide conclusive recommendations for future assisted colonisation sites, but 
shows that assisted colonisation could form part of the conservation toolbox for $P$. umbrina provided that the release site offers suitable aquatic and terrestrial microclimates and abundant food. However, the prospects of long-term survival of $P$. umbrina within southern coastal habitats are less clear. Understanding the biological constraints that affect $P$. umbrina in new habitats (e.g. time to maturity, fecundity, hatchling survival, movement patterns and population growth rates) will be imperative for evaluating if a translocation site will ultimately support a selfsustaining population. Further, the impact of $P$. umbrina on the recipient ecosystem needs to be quantified and monitored. We recommend that future trials initially aim to be conducted over 12-18 mo to evaluate survival, growth, microclimate use and behaviour over the winter-spring activity period, throughout aestivation and once turtles emerge from aestivation at the beginning of the following hydroperiod. These data should then inform a well-resourced assisted colonisation attempt that is subject to regular monitoring to assess biological responses that will be expressed over long time periods - likely decades. Pursuing these recommendations should occur without delay, as assisted colonisations may be the best option for maintaining self-sustaining wild populations of $P$. umbrina as the regional climate rapidly transitions to a drier, hotter state.

\subsection{Conclusions}

As global climates shift too rapidly for many species to evolve and adapt in situ, it becomes increasingly necessary to explore proactive methods of species conservation. This will likely entail moving away from traditional conservation ideologies of maintaining or returning ecosystems to a historical reference state (Hobbs et al. 2009, Thomas 2011). Assisted colonisation is an inherently risky form of translocation (Ricciardi \& Simberloff 2009), but in order to promote its effectiveness for conserving threatened species, trials preceded by detailed planning and research, as occurred here, are critical. This will allow assisted colonisation to move beyond conjecture around its collateral impacts to a fully explored strategy for conferring species with resilience to an unprecedented rate of climate change.

Acknowledgements. Funding was provided by the Australian Government's National Environmental Science Programme through the Threatened Species Recovery Hub, the Department of Biodiversity, Conservation and Attractions (Swan Coastal District), the National Climate Change Adaptation
Research Facility's National Adaptation Network for Natural Ecosystems and the School of Biological Sciences at the University of Western Australia. We thank Don Bradshaw, Clive Digney, Craig Olejnik, Bradley Barton, Ian Wilson and Kim Williams for logistical support, Clive Digney for providing accommodation at East Augusta and Stewart Macdonald, Nicholas Rodriguez, Marcus Lee, Katja Schmöelz and Jian Wang for their assistance with fieldwork. Data on early growth of Pseudemydura umbrina at Perth Zoo were provided by Bradie Durell and Lisa Mantellato, and weather data for Moore River were provided by Ian Foster from the Western Australian Department of Food and Agriculture.

\section{LITERATURE CITED}

Adolph SC, Porter WP (1996) Growth, seasonality, and lizard life histories: age and size at maturity. Oikos 77:267-278

Angilletta JM Jr, Steury TD, Sears MW (2004) Temperature, growth rate, and body size in ectotherms: fitting pieces of a life-history puzzle. Integr Comp Biol 44:498-509

Arnall SG (2018) Assisted migration of the western swamp turtle (Pseudemydura umbrina): using eco-energetics to inform translocation decisions under climate change. PhD dissertation, The University of Western Australia, Perth

Arnall SG, Kuchling G, Mitchell NJ (2015) A thermal profile of metabolic performance in the rare Australian chelid, Pseudemydura umbrina. Aust J Zool 62:448-453

Arnall SG, Mitchell NJ, Kuchling G, Durell B, Kooijman S, Kearney MR (2019) Life in the slow lane? A dynamic energy budget model for the western swamp turtle, Pseudemydura umbrina. J Sea Res 143:89-99

* Avery RA (1978) Activity patterns, thermoregulation and food consumption in two sympatric lizard species (Podarcis muralis and P. sicula) from central Italy. J Anim Ecol 47:143-158

Bickford D, Howard SD, Ng DJJ, Sheridan JA (2010) Impacts of climate change on the amphibians and reptiles of Southeast Asia. Biodivers Conserv 19:1043-1062

* Böhm M, Cook D, Ma H, Davidson AD and others (2016) Hot and bothered: using trait-based approaches to assess climate change vulnerability in reptiles. Biol Conserv 204: $32-41$

* Buckley LB, Ehrenberger JC, Angilletta MJ (2015) Thermoregulatory behaviour limits local adaptation of thermal niches and confers sensitivity to climate change. Funct Ecol 29:1038-1047

Burbidge AA (1967) The biology of south-western Australian tortoises. $\mathrm{PhD}$ dissertation, The University of Western Australia, Perth

Burbidge AA (1981) The ecology of the western swamp tortoise Pseudemydura umbrina (Testudines: Chelidae). Wildl Res 8:203-223

Burbidge AA, Kuchling G, Olejnik C, Mutter L (2010) Western swamp tortoise (Pseudemydura umbrina) recovery plan. Department of Environment and Conservation, Perth

Crawford KM, Spotila JR, Standora EA (1983) Operative environmental temperatures and basking behavior of the turtle Pseudemys scripta. Ecology 64:989-999

CSIRO, Bureau of Meteorology (2018) State of the climate 2018. CSIRO and Bureau of Meteorology, Perth

Dade MC (2013) Can spatial data accurately locate optimal sites for assisted colonisation? Identifying suitable habi- 
tat for the western swamp tortoise (Pseudemydura umbrina) under a changing climate. MSc thesis, University of Western Australia, Perth

* Dade MC, Pauli N, Mitchell NJ (2014) Mapping a new future: using spatial multiple criteria analysis to identify novel habitats for assisted colonization of endangered species. Anim Conserv 17:4-17

Dickinson MG, Orme DL, Suttle KB, Mace GM (2014) Separating sensitivity from exposure in assessing risk from climate change. Sci Rep 4:6898

Emelyanova I, Ali R, Dawes W, Varma S, Hodgson G, McFarlane D (2013) Evaluating the cumulative rainfall deviation approach for projecting groundwater levels under future climate change. J Water Clim Chang 4: 317-337

Georges A, Beggs K, Young J, Doody J (2005) Modelling development of reptile embryos under fluctuating temperature regimes. Physiol Biochem Zool 78:18-30

Gibbons JW, Scott DE, Ryan TJ, Buhlmann KA and others (2000) The global decline of reptiles, déjà vu amphibians. Bioscience 50:653-666

Gibson L, McNeill A, de Tores P, Wayne A, Yates C (2010) Will future climate change threaten a range restricted endemic species, the quokka (Setonix brachyurus), in south west Australia? Biol Conserv 143:2453-2461

Grant BW (1990) Trade-offs in activity time and physiological performance for thermoregulating desert lizards, Sceloporus merriami. Ecology 71:2323-2333

Grayson KL, Dorcas ME (2004) Seasonal temperature variation in the painted turtle (Chrysemys picta). Herpetologica 60:325-336

Hobbs RJ, Higgs E, Harris JA (2009) Novel ecosystems: implications for conservation and restoration. Trends Ecol Evol 24:599-605

Hughes L (2000) Biological consequences of global warming: Is the signal already apparent? Trends Ecol Evol 15: $56-61$

Hyndman RJ, Khandakar Y (2008) Automatic time series forecasting: the forecast package for R. J Stat Softw 26: $1-22$

IUCN/SSC (Species Survival Commission) (2013) Guidelines for reintroductions and other conservation translocations, version 1.0. IUCN Species Survival Commission, Gland

King JM, Kuchling G, Bradshaw SD (1998) Thermal environment, behaviour, and body condition of wild Pseudemydura umbrina (Testudines: Chelidae) during late winter and early spring. Herpetologica 54:103-112

Kingsolver JG, Diamond SE, Buckley LB (2013) Heat stress and the fitness consequences of climate change for terrestrial ectotherms. Funct Ecol 27:1415-1423

Lucas J, Burbidge AA, Graham M, Leung S, Lindgren E, Phillips B (1963) Ecology and conservation of Pseudemydura umbrina. BSc (Hons) group report, The University of Western Australia, Perth

Lunt ID, Byrne M, Hellmann JJ, Mitchell NJ and others (2013) Using assisted colonisation to conserve biodiversity and restore ecosystem function under climate change. Biol Conserv 157:172-177

McFarlane D, George R, Ruprecht J, Charles S, Hodgson G (2020) Runoff and groundwater responses to climate change in south west Australia. J R Soc West Aust 103: 9-27

McLachlan JS, Hellmann JJ, Shchwartz MW (2007) A framework for debate of assisted migration in an era of climate change. Conserv Biol 21:297-302

*Meynecke J (2004) Effects of global climate change on geographic distributions of vertebrates in North Queensland. Ecol Modell 174:347-357

Mitchell NJ, Jones TV, Kuchling G (2012) Simulated climate change increases juvenile growth in a Critically Endangered tortoise. Endang Species Res 17:73-82

Mitchell N, Hipsey MR, Arnall S, McGrath G and others (2013) Linking eco-energetics and ecohydrology to select sites for the assisted colonization of Australia's rarest reptile. Biology (Basel) 2:1-25

* Mitchell NJ, Rodriguez N, Kuchling G, Arnall SG, Kearney MR (2016) Reptile embryos and climate change: modelling limits of viability to inform translocation decisions. Biol Conserv 204:134-147

* Parmesan C (2006) Ecological and evolutionary responses to recent climate change. Annu Rev Ecol Evol Syst 37: 637-669

Parmesan C, Yohe G (2003) A globally coherent fingerprint of climate change impacts across natural systems. Nature 421:37-42

พ Pecl GT, Araújo MB, Bell JD, Blanchard J and others (2017) Biodiversity redistribution under climate change: impacts on ecosystems and human well-being. Science 355: eaai9214

* Pereira HM, Leadley PW, Proença V, Alkemade R and others (2010) Scenarios for global biodiversity in the $21^{\text {st }}$ century. Science 330:1496-1501

* Philip P, Yu B (2020) Interannual variations in rainfall of different intensities in south west of Western Australia. Int J Climatol 40:3052-3071

*Pittman SE, Dorcas ME (2009) Movements, habitat use, and thermal biology of an isolated population of bog turtles (Glyptemys muhlenbergii). Copeia 2009(4):781-790

*Pratchett MS, Bay LK, Gehrke PC, Koehn JD and others (2011) Contribution of climate change to degradation and loss of critical fish habitats in Australian marine and freshwater environments. Mar Freshw Res 62:1062-1081

R Core Team (2017) R: a language and environment for statistical computing. R Foundation for Statistical Computing, Vienna

Rhodin AGJ, Stanford CB, van Dijk PP, Eisemberg C and others (2018) Global conservation status of turtles and tortoises (Order Testudines). Chelonian Conserv Biol 17: 135-161

Ricciardi A, Simberloff D (2009) Assisted colonization is not a viable conservation strategy. Trends Ecol Evol 24: 248-253

Schmölz K (2018) Assisted colonization of juvenile western swamp turtle Pseudemydura umbrina into novel wetlands: macro invertebrate communities, biomass and turtle diet. MSc Thesis, University of Vienna

Seddon PJ (2010) From reintroduction to assisted colonization: moving along the conservation translocation spectrum. Restor Ecol 18:796-802

Seddon PJ, Moro D, Mitchell NJ, Chauvenet ALM, Mawson PR (2015) Proactive conservation or planned invasion? Past, current and future use of assisted colonisation. In: Armstrong D, Hayward M, Moro D, Seddon P (eds) Advances in reintroduction biology of Australian and New Zealand Fauna. CSIRO Publishing, Melbourne, p 105-126

Sinervo B, Mendez-de-le-Cruz F, Miles DB, Heulin B and others (2010) Erosion of lizard diversity by climate change and altered thermal niches. Science 328:894-899 
Thomas CD (2011) Translocation of species, climate change, and the end of trying to recreate past ecological communities. Trends Ecol Evol 26:216-221

Thomas CD, Cameron A, Green RE, Bakkenes M and others (2004) Extinction risk from climate change. Nature 427: 145-148

Urban MC (2015) Accelerating extinction risk from climate change. Science 348:571-573

Urban MC, Richardson JL, Freidenfelds NA (2014) Plasticity and genetic adaptation mediate amphibian and reptile responses to climate change. Evol Appl 7: 88-103

Walther GR, Post E, Convey P, Menzel A and others (2002)

Editorial responsibility: Michael Mahony,

Callaghan, New South Wales, Australia
Ecological responses to recent climate change. Nature 416:389-395

*Williams SE, Shoo LP, Isaac JL, Hoffmann AA, Langham G (2008) Towards an integrated framework for assessing the vulnerability of species to climate change. PLOS Biol 6:e325

Zug GR, Vitt LJ, Caldwell JP (2001) Herpetology: an introductory biology of amphibians and reptiles. Elsevier Science, San Diego, CA

Zuo W, Moses ME, West GB, Hou C, Brown JH (2012) A general model for effects of temperature on ectotherm ontogenetic growth and development. Proc R Soc B 279: $1840-1846$

Submitted: April 4, 2020; Accepted: July 1, 2020

Proofs received from author(s): September 4, 2020 